\title{
Band-selective hetero- and homonuclear cross-polarization using trains of shaped pulses
}

\author{
Erik R.P. Zuiderweg*, Lei Zeng, Bernhard Brutscher** and Robert C. Morshauser \\ Biophysics Research Division and Department of Bulogical Chemistry, The University of Michigan, \\ 930 North University Avenute, Ann Arbor, MI 48109, US A. \\ Received 12 February 1996 \\ Accepted 9 May 1996
}

Keywords: TOCSY; Hartmann Hahn; Protein side-chain assignments; Triple-resonance

\begin{abstract}
Summary
The performance of solution cross-polarization using trains of shaped pulses on two channels is investigated by computer simulation and experiment. It is determined that a Waltz modulation pattern of Gaussian pulses of individual flip angles of $225^{\circ}$, issued to two coupled spins simultaneously, yields excellent coherence transfer with good phasing behavior. Simulations and experimental verification were carried out for both heteronuclectr cross-polarization between two restricted areas (e.g. ${ }^{~} \mathrm{H}^{\alpha}-{ }^{13} \mathrm{C}^{\alpha}$ ) and for homonuclear cross-polarization between two spectral regions $\left(\mathrm{eg} \cdot{ }^{13} \mathrm{CO}-{ }^{13} \mathrm{C}^{6 \mathrm{f}}\right.$ ). It is shown that shaped cross-polarization behaves as pure heteronuclear cross-polarization when the two radiofrequency ( $\mathrm{r}$ ) fields are far apart, while it behaves in some aspects analogous to homonuclear cross-polarization when the two rf fields approach each other. The novel coherence-transfer sequence, referred to as 'cosine-modulated shaped Waltz' (CSW), was implemented in a $3 \mathrm{D}(\mathrm{H}) \mathrm{C}(\mathrm{CCO}) \mathrm{NH}$ experiment using an $18-\mathrm{kDa}$ isotopically labeled protein.
\end{abstract}

\section{Introduction}

Heteronuclear cross-polarization (HCP) in solution (Bertrand et al., 1978; Muillex and Ernst, 1979) has become easy to implement with the introduction of simultaneous windowless pulse trains on two channels (Bearden and Brown, 1989; Zuiderweg, 1990; Brown and Sanctuary, 1991; Ernst et al., 1991). The technique has been successfully applied, for example, for ${ }^{1} \mathrm{H}-{ }^{13} \mathrm{C}$ transfers in $\mathrm{HCCH}-$ type experiments (Majumdar et al., 1993; Schwendinger et al., 1994; Wijmenga et al., 1995), for ${ }^{1} \mathrm{H}_{-}{ }^{31} \mathrm{P}$ transfers in ${ }^{31} \mathrm{P}$-driven assignment schemes for nucleic acids (Kellog, 1992; Kellog and Schweitzer, 1993) and for ${ }^{13} \mathrm{C}^{-15} \mathrm{~N}$ transCer in triple-resonance experiments (Richardson et al., 1993; Mariani et al., 1994). Simultaneous triple-resonance cross-polarization between ${ }^{1} \mathrm{H},{ }^{13} \mathrm{C}$ and ${ }^{15} \mathrm{~N}$ has also been demonstrated (Majumdar and Zuiderweg, 1995). The reasons for the use of the HCP coherence-transfer method instead of pulsed free-precession (INEPT) are advantages with respect to better tolerance to $f f$ inhomogeneity, slow- er rclaxation because of less contribution of antiphase terms during transfer and because of the suppression of exchange-broadening in HCP (Krishnan and Rance, 1995; Majumdar and Zuiderweg, 1995). HCP can be used to advantage for efficiently transferring magnetization between more than two spins in a coupled network, analogous to the use of TOCSY or Homonuclear HartmannHajen in proton NMR applications (Braunschweiler and Ernst, 1983; Bax and Davis, 1985). For example, good sensitivity gains can be obtained in $\mathrm{H}(\mathrm{CCACO}) \mathrm{NH}$ experiments, where initial ${ }^{1} \mathrm{H} \rightarrow{ }^{13} \mathrm{C}$ cross-polarization magnetization injection already accomplishes significant ${ }^{13} \mathrm{C} \rightarrow{ }^{13} \mathrm{C}$ transfer. The HCP technique is not without drawbacks as it is difficult (Majumdar and Zuiderweg, 1995) to concatenate successive transfer steps, as is so elegantly done in the INEPT-based constant-time tripleresonance experiments (e.g. Kay et al., 1991). Moreover, in HCP, it is impossible to sample the frequency of the nuclei during the transfer process. These drawbacks limit the sensitivity-gain potential of HCP to sequences that

\footnotetext{
*To whom correspondence should be addressed.

** On leave from the Institut de Biologie Structurale-Jean-Pierre Fbel, Grenoble, France.

Supplenentary Material comprising six figures is available upon request.
} 
use in-phase transfers between nonsampled nuclei. Radiofrequency (rf) power requirements are not amongst the drawbacks, as HCP is even being considered for imaging applications (Artemov et al., 1995).

From a different perspective, $\mathrm{HCP}$ can be used as a semiselective transfer technique: for instance, low-power multiple-pulse ${ }^{13} \mathrm{C}^{\alpha}{ }_{-}^{15} \mathrm{~N}$ transler can be performed in a sensitive way in fully labeled proteins as the ${ }^{12} \mathrm{C}^{12}{ }^{13} \mathrm{C}^{\natural}$ coupling is suppressed (Majumdar and Zuiderweg, 1995). Selective transfers have also been used for the ${ }^{13} \mathrm{C}^{13} \mathrm{C}$ correlation in fully labeled nucleic acids (Farmer, 1995). These methods have been refined by Glaser and coworkers in their TACSY techniques (Quant et al., 1995). HCP can also be used as a totally selective transfer method between two resonances in a homonuclear spin system: Bodenhausen and co-workers (Konrat et al, 1991; Vincent et al., 1993) show that the use of a cosinemodulated weak continuous wave (CW) field centered between two coupled resonances of interest can quantitatively transfer magnetization between the coupled resonances. Recently, Shirikawa et al. (1995) reported the use of sequences that use simultaneous trains of rectangular pulses at low power to achieve semiselective cross-polarization between two regions in a homonuclear spin system. Grzesiek and Bax (1995) have shown that such dual selectivity of a square-shaped rf field can also be obtained by orthogonal audio-frequency modulation.

In this report, we investigate the design of band-selective cross-polarization sequences using shaped pulses. A similar study is presented in the accompanying paper by Carlomagno et al. (1996). The object is to transfer magnetization between two spectral bands by cross-polarization between spins of the same species: ${ }^{13} \mathrm{C}^{\alpha}-{ }^{13} \mathrm{CO}$ in labeled proteins, ${ }^{1} \mathrm{H}^{\alpha_{-}{ }^{1}} \mathrm{HN}$ in unlabeled peptides and proteins and ${ }^{13} \mathrm{C}^{\beta}{ }^{13} \mathrm{C}^{\text {arom }}$ in labeled aromatics (the latter is demonstrated by Carlomagno et al. (1996)). Improved selective heteronuclear transfer into a coupled homonuclear system (e.g. ${ }^{15} \mathrm{~N}-{ }^{13} \mathrm{C}$ ) without magnetization diffusion into the homonuclear system may also be an application. The experimental set-up is straightlorward: a train of shaped pulses, modulated in e.g. a MLEV-type pattern, is delivered simultaneously at two spectral regions in a homonuclear spectrum (Zuiderweg, 1994). In principle, this can be carried out from two different amplifiers in the spectrometer, but is more easily performed from a single channel with a single pulse train that is cosinemodulated with half the difference frequency. This approach should allow improved selectivity of transfer over sequences using rectangular pulses (Shirakawa et al., 1995), while it would allow bandwidth improvement as compared with the $\mathrm{CW}$ techniques of Bodenhausen and co-workers (Konrat et al., 1991; Vincent et al., 1993). However, several questions need to be investigated before such a sequence can be designed properly: will a sequence of e.g. Gaussian pulses actually transfer magnetization afficicntly? The radiofrequency power varies in such scquences and may at low amplitude not be sufficient to suppress chemical shift evolution. This may result in slow transfer and/or in incomplete transfer. The CW HCP Hamiltonian with sufficient rf field strength and Hartmann-Hahn match along the $\mathrm{x}$-axes, behaves, in the doubly-rotating of frame with no resonance offsets as pure scalar coupling of the form:

$$
H=2 \pi J_{I S} I_{y} S_{y}+2 \pi J_{I S} I_{z} S_{z}
$$

producing the transfer

$$
\begin{aligned}
\mathrm{I}_{\mathrm{x}} \stackrel{\mathrm{HCP}}{\longrightarrow} & \frac{\mathrm{I}_{\mathrm{x}}}{2}\left(1+\cos \pi \mathrm{J}_{\mathrm{IS}} \tau\right)+\frac{\mathrm{S}_{\mathrm{x}}}{2}\left(1-\cos \pi \mathrm{J}_{\mathrm{IS}} \tau\right) \\
& +\frac{1}{2}\left(2 \mathrm{~S}_{z} \mathrm{I}_{y}-2 \mathrm{~S}_{\mathrm{y}} \mathrm{I}_{z}\right) \sin \pi \mathrm{J}_{\mathrm{IS}} \tau
\end{aligned}
$$

with complete in-phase transler $I_{x} \rightarrow S_{x}$ occurring at time $\tau=I / J$ (Braunschweiler and Ernst, 1983).

Can such complete in-phase transfer also be achieved for shaped-pulse cross-polarization? What is the transfer rate for shaped CP? Does the transfer maximum occur at a mixing time $1 / 2 \mathrm{~J}$, as for homonuclear $\mathrm{CP}$, at a time $1 / \mathrm{J}$, as for heteronuclear $\mathrm{CP}$, or in between? Homonuclear CP is isotropic in the sense that in an I-S spin system, $I_{v}$ magnetization is transferred to $S_{w}$ where $v=x, y$ or $z$, irrespective of the orientation of the locking lield (Braunschweiler and Ernst, 1983). Heteronuclear CP is anisotropic in the sense that only I magnetization components aligned with the ' $\mathrm{I}$ ' If field are transferred and emerge along the ' $S$ ' rf field (Zuiderweg, 1990). How will a shaped-pulse CP behave in this respect? How will "spinlocking' with shaped pulses affect the phases of the signals and over what bandwidth? And how will the rf field centered on spins I inlerfere with the nutation of the spins $\mathrm{S}$ and vice versa?

Parameters affecting these properties include pulse shape, flip angle per pulse, phase or amplitude modulation scheme, permutation scheme and if power (restricting the problem to identical pulse trains on the two spins). This multivariable probiem can in principle be approached with e.g. a genetic algorithm using desirable properties such as efficient, in-phase transfer over a practical spectral range (e.g. $30 \mathrm{ppm}$ ) between two spectral regions that are $125 \mathrm{ppm}$ apart as a fittess function. However, since our current computers are not fast enough for such an optimization, we had to follow a more intuitive approach.

Using a numerical simulation of the behavior of a twospin system under the presence of two $r f$ fields, we first searched for the best flip angle for Gaussian pulses in a pure heteronuclear transfer. This was followed by the investigation of different modulation and permutation schemes and their effects on the transfer properties. The 

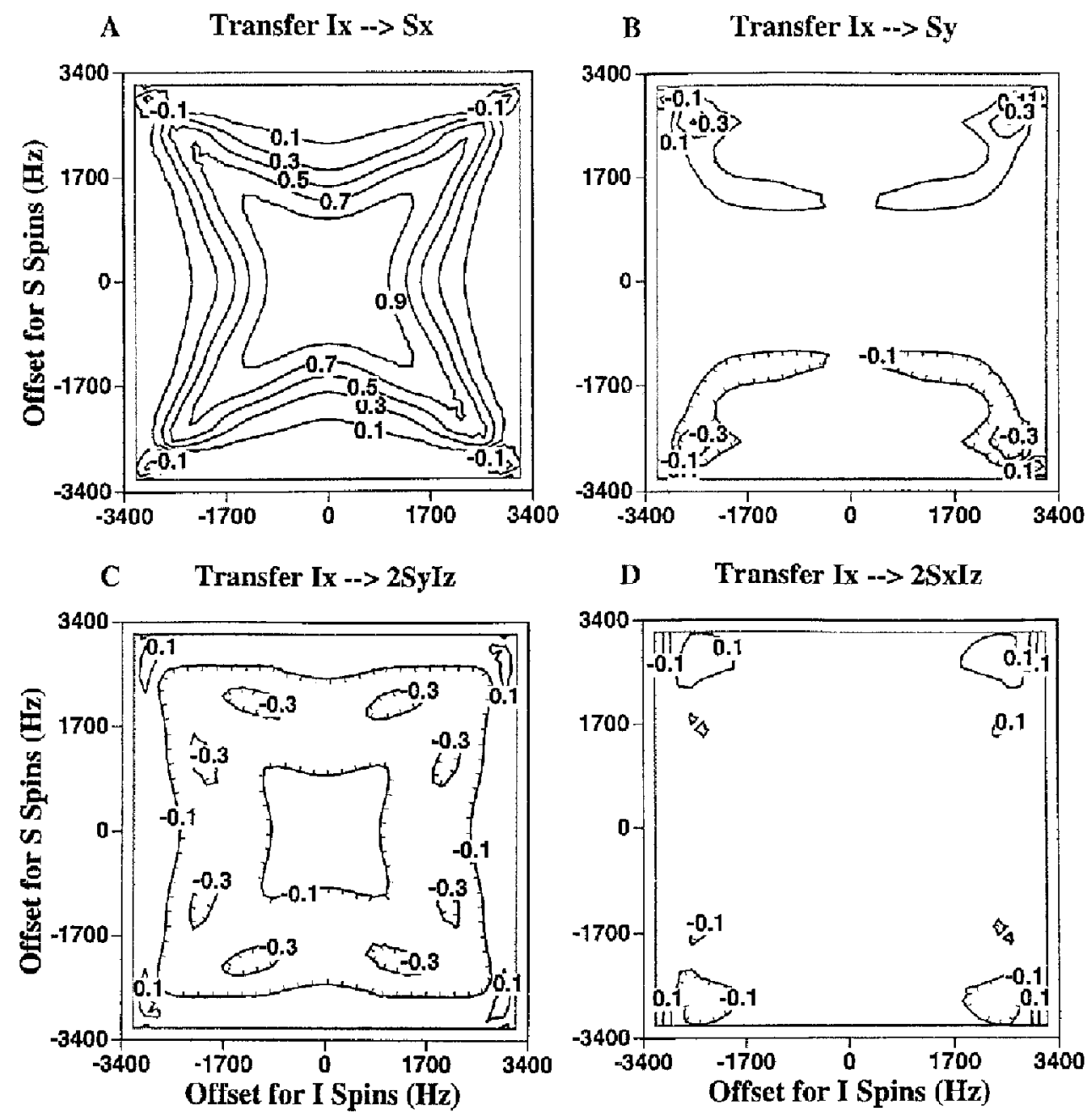

Fig. 1. Simulation of heteromaclear cross-polarization $I \rightarrow S$ using trains of shaped pulses. The Hamiltonian of Eq. 3 was used with a scalar coupling of $55 \mathrm{H}$. Initial state: $\mathrm{I}_{\text {. }}$. A Waltz train of Gaussian rf pulses was used along the $\mathrm{x}$-axes of both the $\mathrm{I}$ and $\mathrm{S}$ tesonances utilizing the scheme ( 342312423 ) repeated in an $A B B A$ pattern. The individual Gaussians (truncation level 1\%) had pulse lengths of $333 \mu s$, with a peak If of $4.6 \mathrm{kH} z$ corresponding to a fip angle of $225^{\circ}$. The magnetization components $\mathrm{S}_{\mathrm{x}}(\mathrm{A}), \mathrm{S}_{\mathrm{y}}(\mathrm{B}), 2 \mathrm{~S}_{\mathrm{y}} \mathrm{I}_{z}$ (C) and $2 \mathrm{~S}_{\mathrm{x}} \mathrm{I}_{\mathrm{z}}$ (D) are shown as a function of offset for both the donating ( $\mathrm{I}$, vertical axis) and receiving $(\mathrm{S}$, horizontal axis) spins at a mixing time of $18.33 \mathrm{~ms}(=1 / \mathrm{J})$.

findings for the heteronuclcar case were subsequently verified by experiment. Then, with the heteronuclear transfer scheme in hand, we investigate by simulation and by experiment the questions associated with band-selective transfer in the homonuclear system. Finally, we show an application of such homonuclear cross-polarization using shaped pulses in a triple-resonance sequence for a larger ${ }^{13} \mathrm{C},{ }^{15} \mathrm{~N}$-labeled protein.

\section{Shaped-pulse-based band-selective heteronuclear cross-polarization}

\section{Simulation}

The Hamiltonian for a heteronuclear IS spin system in the presence of two amplitude-modulated rf fields, each inluencing only their own spin, is in the doubly rotating frame given by:

$$
H(t)=\Omega_{I} I_{z}+\Omega_{S} S_{r .}+2 \pi J_{I S} I_{z} S_{z}+\omega_{r f}^{I}(t) I_{x}+\omega_{r f}^{S}(t) S_{x}
$$

where $\Omega_{\mathrm{I}}$ and $\Omega_{\mathrm{S}}$ are the resonance offsets for the I and $S$ spins, respectively, and where $\omega_{\mathrm{r}}^{\mathrm{T}}(\mathrm{t})$ and $\omega_{\mathrm{rf}}^{\mathrm{s}}(\mathrm{c})$ terms contain the amplitude modulation of the rf fields. Only when the rf amplitudes are large and constant, the transformation to the if frame can be made for an effective Hamiltonian as given by Eq. 1. In the present case, we choose to keep the Hamiltonian in the form of Eq. 3 and use it to compute the evolution of the spin system from:

$$
d \rho(t) / d t=-i[\rho(t), H(t)]
$$

using a simple numerical integration:

$$
\rho(t+\delta t)=\rho(t)-i[\rho(t), H(t)] \delta t
$$

In order for the integration to behave properly, the time step $\delta$ t was commonly taken to be 10000 times smaller than the inverse of the largest term in the Hamiltonian 

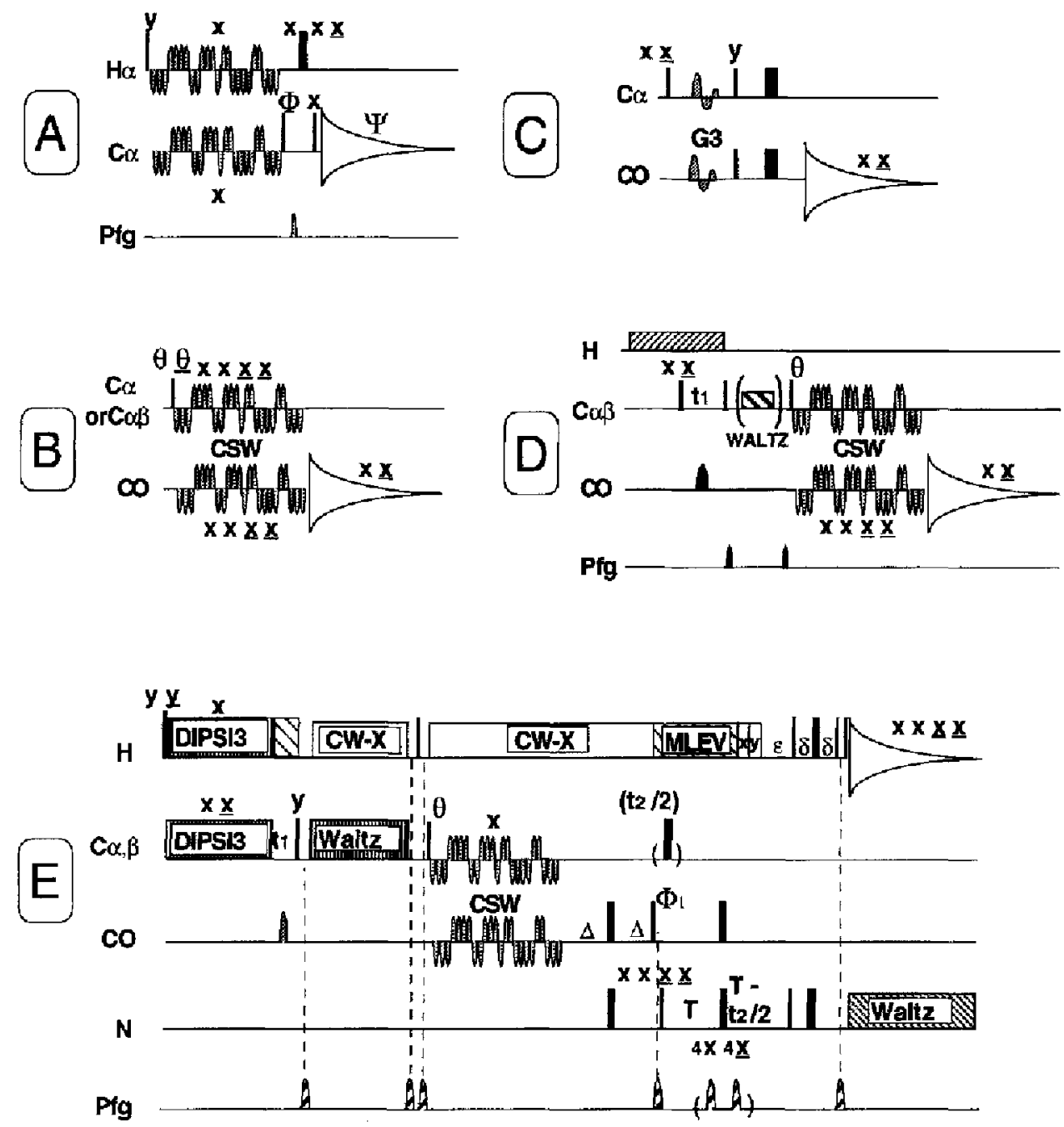

Fig. 2. Pulse sequences used in this work. (A) Investigation of heteronuclear cross-polarization $I \rightarrow S$ using trains of shaped pulses. All black boxes are $\mathrm{T}$ pulses of $90^{\circ}$ llip angle. The magnetization at the receiving $S$ spin is interrogated using gradient-z-filters combined with antiphase selection/suppression. $S_{x}$ is monitored with $\phi=y_{s} \Psi=+,+; S_{y}$ with $\phi=x, \Psi=+,+; S_{x} I_{z}$ with $\phi=y, \Psi=+,-; 2 S, I_{z}$ with $\phi=x, \Psi=+,-$. (B) Simple sequence for band-selective homonuclear cross-polarization. The first pulse in our application on the ${ }^{13} \mathrm{C}^{\infty}$ or ${ }^{13} \mathrm{C}^{\alpha, \beta}$ nucle is issued with the carrier at that position and is calibrated to leawe the ${ }^{13} \mathrm{CO}$ spins unperturbed. The rf earrier position is subsequently shifted to the ${ }^{13} \mathrm{CO}$ position and the $\mathrm{CSW}$ pulse is issued at the center frequency between ${ }^{13} \mathrm{C}^{8}$ and ${ }^{13} \mathrm{CO}$ by applying a frequency shift with a phase ramp. Care was taken to have the ${ }^{13} \mathrm{C}$ excitation pulse and the ${ }^{13} \mathrm{C}^{\alpha}$ 'leg' of the $\mathrm{CSW}$ field at exactly the same frequency. Since our equipment produces frequency shifts in a phasecontinuous mode, phase coherence is retained between these two fields; however, the value of the phase shift between the two fields is unknown a priori, but was deternined to be $50^{\circ}$. Also, due to the careful placement of the carrier, the ${ }^{13} \mathrm{CO}$ 'leg' of the CSW field is phase-coherent with the receiver, and the FID can thus be accumulated from transient to transient. (C) A refocussed INFPT experiment with ${ }^{13} \mathrm{C}^{\alpha}-{ }^{13} \mathrm{C}^{13}$ (ecoupling, transferring ${ }^{13} \mathrm{C}^{\alpha}$ coherence to ${ }^{13} \mathrm{CO}$ coherence $\mathrm{All}{ }^{13} \mathrm{C}$ pulses are applied as squared selective pulses adjusted in such a way that they do not excite the other nucleus $\left({ }^{13} \mathrm{C}^{8}\right.$ or ${ }^{17} \mathrm{CO}$, respectively), except for the pair of 180 's in the first half of the experiment. These latter pulses were issued as a single 2-ms 180 pulse, shaped as a G-3 cascade (Emsley and Bodenhausen, 1990; McCoy, 1995) and cosine-modulated to simultaneously invert the ${ }^{13} \mathrm{C}^{\alpha}$ and ${ }^{13} \mathrm{CO}$ spins, hence inactivating most of the ${ }^{13} \mathrm{C}^{\alpha}{ }^{13} \mathrm{C}^{\beta}$ couplings. (D) and (E) Pulse sequences of the 2D CCO test sequence (D) and the 3D (H)C(CCO)NH experiment $(\mathrm{E})$. All ${ }^{13} \mathrm{C}$ pulses are applied as squared selective pulses adjusted in such a way that they do not excite the other nucleus $\left({ }^{17} \mathrm{C}^{\alpha}\right.$ or ${ }^{13} \mathrm{CO}$, respectively). Exceptions are the two $90^{\circ} \mathrm{z}$-filter pulses after the initial ${ }^{1} \mathrm{H}-{ }^{13} \mathrm{C}$ CP transfer in sequence (E), which were applied as 16- $\mu$ s hard pulses and the ${ }^{13} \mathrm{CO}$ refocussing pulse during $\mathrm{t}_{1}$, which was applied as a $200-\mu s$ pulse with a Gaussian shape centered on ${ }^{13} \mathrm{C}^{\alpha}$ but cosine-modulated to invert the ${ }^{13} \mathrm{CO}$ spins while compensating for the Bloch-Siegett shift (sequence (D)). In both experiments, the ${ }^{13} \mathrm{C}$ carrier is switched from the ${ }^{13} \mathrm{C}^{\alpha . \beta}(42 \mathrm{ppm})$ to the ${ }^{13} \mathrm{CO}(176 \mathrm{ppm})$ position, as described above at the beginning of the CSW mixing sequence. By using a phase ramp, the frequency of the CSW pulse was moved to the center frequency of 109 ppm (see also legend to Fig. 2B). The other carrier f.requencies used in sequence (F) are: ${ }^{1} \mathrm{H}\left(3 \mathrm{ppm}\right.$ during the CP transfer, $4.8 \mathrm{ppm}$ and $8.1 \mathrm{ppm}$ for final excitation pulse) and ${ }^{15} \mathrm{~N}(119 \mathrm{ppm})$. For the initial ${ }^{1} \mathrm{H}^{13} \mathrm{C}$ transfer one cycle of a DIPSI-3 scheme (Shaka et al, 1988$)$ is used (6.8 ms at of fields of $8.5 \mathrm{kHz}$ ); homonuclear ${ }^{13} \mathrm{C}$ mixing was achieved using fout loops of a Walkz-16 mixing scheme (11.6 ms at an if field of $7 \mathrm{kHz}$ ). A CSW pulse is applied for $18.33 \mathrm{~ms}$ at a peak power level of $4.6 \mathrm{kHz}$ per nuclcus for sequence (D), corrcsponding to 333- $\mu_{\mathrm{s}}$ Gaussians of $225^{\circ}$. For sequence (E), CSW was applied for $19.2 \mathrm{nns}$ at $7 \mathrm{kHz}$, per nucleus, corresponding to 200 - $\mu \mathrm{s}$ Gauszians of $225^{\circ}$. The other transfer delays are optimized to $\Delta=13 \mathrm{~ms}, \mathrm{~T}=12 \mathrm{~ms}, \mathrm{E}=5.4 \mathrm{~ms}$ and $\delta=2.25 \mathrm{~ms}$. Pulsed field gradients ( $\mathrm{P} F \mathrm{G}, 15-20 \mathrm{G} / \mathrm{cm}$, durations: $200 \mu \mathrm{s}-600 \mu \mathrm{s}$ ) are used for water suppression and coherence-pathway selcction. A phase correction $\left(\Phi_{3}\right)$ of $30^{\circ}$ was applied to get optimal transfer intensity. A basic eight-step phase cycle is used, as indicated in the sequence, PFG around refocussing pulses can be used to reduce this minimun phase cycle to four steps. Quadrature detection is obtained by changing the phases of $\Phi_{1}\left(t_{1}\right)$ and $\Phi_{2}\left(t_{2}\right)$ in the States-TPPI manner (Marion et al., 1989). 


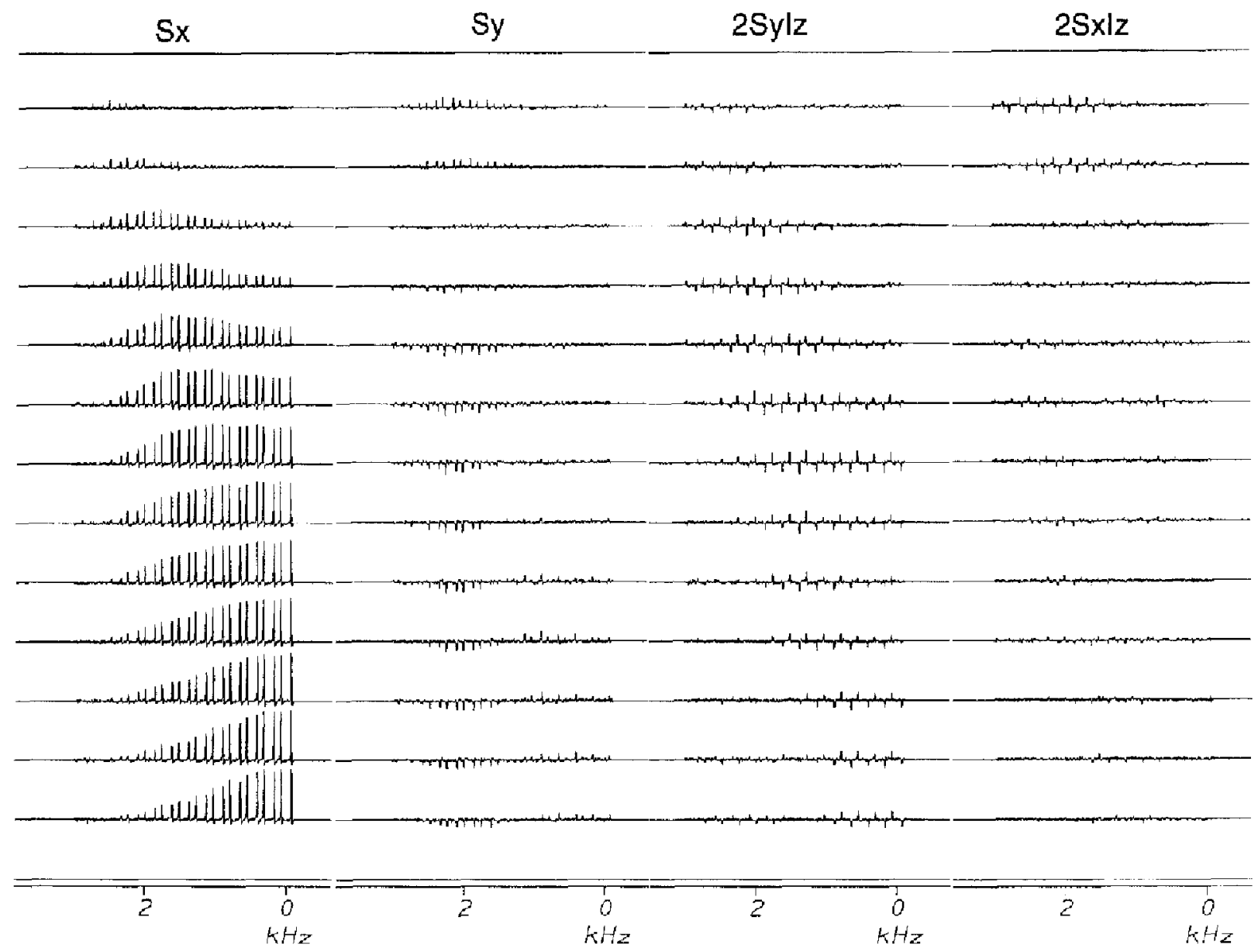

Fig. 3. Experimental verification of heteronuclear cross-polarization using a Waltz train of Gaussian rf pulses of $300 \mu s$ with a nominal lip angle of (approximately) $225^{\circ}$ utilizing the scheme ( $3 \underline{4} 2 \underline{3} 12 \underline{2} 42$ 3) repeated in an $\mathrm{ABB} A$ pattern. A $100-\mathrm{mM}$ sample of unlabeled alanize in ${ }^{2} \mathrm{H}_{2} \mathrm{O}$

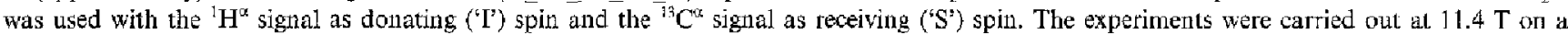
Bruker AMX-500 spectrometer using a 5-mm broadband probe and a BSV-10 amplifier in the CW mode. The peak rf was approximately $5 \mathrm{kEl}$ for both the proton and the carbon channel. The ${ }^{13} \mathrm{C}^{a}$ magnetization was interrogated with the pulse sequences of Fig. $2 \mathrm{~A}$ after a mixing time of $7.3 \mathrm{~ms}$ (1/J for this hetcronuclear coupling). Vertical axis: $\mathrm{rf}$ offset of the ' $\mathrm{H}$ carrier in increments of $240 \mathrm{~Hz}$ from the (donating) Ala ${ }^{\prime} \mathrm{II}{ }^{\alpha}{ }^{\mathrm{r}}$ resonance. Horizontal axis: if offset of the ${ }^{13} \mathrm{C}$ carrier from the (receiving) Ala ${ }^{13} \mathrm{C}^{\alpha}$ resonance. The vertical scale is identical in all panels.

(usually the chemical shift of (sets $\Omega_{\mathrm{I}}$ and $\Omega_{\mathrm{s}}$ ). Typically, we use a density matrix $I_{2}$ as a starting situation, apply the of fields along the $x$-axes, and poll for the expectation values of the magnetization components $\mathrm{M}_{\mu}$ of interest during the simulation using:

$$
<\mathrm{M}_{\mu}>(\mathbf{t})=\operatorname{Tr}\left\{\rho(t) \mathrm{M}_{\mu}\right\}
$$

where $M_{\mu}$ is, for instance, $S_{x}, S_{y}, 2 S_{x} I_{z}$ or $2 S_{y} I_{z}$.

The simulations showed that good behavior is found for Gaussian pulses, each with a nominal fip angle of $225^{\circ}$, modulated in a Waltz-16 pattern (Shaka et a1., 1983). The actually used scheme is $342 \underline{2} 12423$, permuted in an ABBA-type pattern (Levitt et a1., 1982), where e.g. a ' 3 ' unit consists of three Gaussian pulses of the same phase, length and amplitude in a row. Figure 1 shows the transfer efficiency of this scheme for the various magnetization components as a function of two $\mathrm{rf}$ field offsets, plotted at the transfer time of $\tau=1 / J$. This time yields maximum transfer for small offsets; slightly longer times are needed for maximum transfer for offscts over $1 \mathrm{kHz}$ (see Supplementary Material). At $\tau=1 / \mathrm{I}$, transfer $I_{x} \rightarrow S_{x}$ is seen to be more than $90 \%$ efficient over a square range of $2 \mathrm{kHz}$. Over this same range, the antiphase dispersion component $2 \mathrm{~S}_{y} \mathrm{I}_{\mathrm{z}}$ is less than $10 \%$, the dispersion component $S_{y}$ is less than $10 \%$, while the antiphase absorption component $2 S_{x} I_{z}$ is very close to zero. Heteronuclear shaped pulse cross-polarization transfer thus closely resembles the $\mathrm{CW}$ case where the antiphase component $2 S_{y} I_{z}$ is zero when the in-phase component $S_{x}$ is maximal at a time of $\tau=1 / \mathrm{J}$ (see Eq. 2). The predictions obtained from the simulations are very encouraging. Net transfer can be obtained over an appreciable spectral area of at least $2 \mathrm{kH} z\left(16 \mathrm{ppm}\right.$ for ${ }^{13} \mathrm{C}$ at $\left.11.4 \mathrm{~T}\right)$ and very little magnetization is lost in undesirable components. The fact that the shaped if field drops periodically below the value of the chemical shift offset, does not affect the efficiency of transfer to a large extent. 
Changing the flip angle of the Gaussian pulses to values other than $225^{\circ}$ (by changing the pulsc length) resulted in decreased transfer efficiency, while a pure $S_{x}$ phase signal was hard to obtain at any point in time (see Supplementary Material). Rationalization for the superior behavior of the 225 Gaussian pulse in this scheme may be found in the fact that a single $225^{\circ}$ Gaussian pulse is self-refocussing to a large extent (better than a $270^{\circ}$ Gaussian pulse; Emsley and Bodenhausen, 1989). A pure MLEV-type modulation scheme (Levitt et al., 1982) created more dispersion behavior than the Waltz modulation, hence our choice of Waltz (see Supplementary Material).

\section{Verification}

Figure $2 \mathrm{~A}$ shows the pulse sequence used for the verification of the heteronuclear shaped cross-polarization. Figure 3 shows the results for ${ }^{1} \mathrm{H} \mathrm{I}^{13} \mathrm{C}$ transfer using the natural abundance ${ }^{1} \mathrm{H}^{\alpha}-{ }^{13} \mathrm{C}^{\alpha}$ spin system in a $100-\mathrm{mM}$ alanine sample. The results show that the numerical predictions are born out in the practical case. In-phase transfer is seen to have the predicted range of usable transfer, even reproducing the widening of the bandwidth at larger offsets. The undesirable magnetization components are small in the predicted $1 \mathrm{kHz} \times 1 \mathrm{kHz}$ range $(2 \mathrm{kHz} \times 2 \mathrm{kHz}$ square). As simulation predicts, the $2 \mathrm{~S}_{\mathrm{y}} \mathrm{I}_{z}$ component is the largest of the undesirable components. The excellent agreement between simulation and experiment is somewhat surprising, since deviations were expected in practice because of a non-uniform flip angle over the sample due to $\mathrm{rf}$ inhomogeneity and/or non-ideal pulse shapes. We conclude that for the truly heteronuclear case, the experiments verify very closely the predictions on the basis of the computer simulations.

\section{Shaped-pulse-based band-selective homonuclear cross- polarization}

\section{Simulation}

For a homonuclear IS spin system subjected to two of fields, the expression for the Hamiltonian in the doubly rotating frame is given by:

$$
\begin{aligned}
& H(t)=\Omega_{1} I_{t}+\omega_{\mathrm{ri}}^{\mathrm{l}}(\mathrm{t}) \mathrm{I}_{\mathrm{x}}+\omega_{\mathrm{rf}}^{\mathrm{s}}(\mathrm{t})\left[\mathrm{I}_{\mathrm{x}} \cos \Omega_{\mathrm{ri}} \mathrm{t}+\mathrm{I}_{\mathrm{y}} \sin \Omega_{\mathrm{rf}} \mathrm{t}\right] \\
& +\Omega_{\mathrm{S}} \mathrm{S}_{\mathrm{z}}+\omega_{\mathrm{rf}}^{\mathrm{S}}(\mathrm{t}) \mathrm{S}_{\bar{z}}+\omega_{\mathrm{rf}}^{\mathrm{I}}(\mathrm{t})\left[\mathrm{S}_{\mathrm{z}} \cos \Omega_{\mathrm{rf}} \mathrm{t}-\mathrm{S}_{\mathrm{y}} \sin \Omega_{\mathrm{rf}} \mathrm{t}\right] \\
& +2 \pi \mathrm{J}_{\mathrm{IS}} \mathrm{I}_{\mathrm{z}} \mathrm{S}_{\mathrm{z}}+2 \pi \mathrm{J}_{\mathrm{IS}}\left[\mathrm{I}_{\mathrm{s}} \mathrm{S}_{\mathrm{x}}+\mathrm{I}_{\mathrm{y}} \mathrm{S}_{\mathrm{y}}\right] \cos \Omega_{\mathrm{rf}} \mathrm{t} \\
& \left.+2 \pi \mathrm{J}_{\mathrm{TS}} \mathrm{I}_{\mathrm{y}} \mathrm{S}_{\mathrm{x}}-\mathrm{I}_{\mathrm{x}} \mathrm{S}_{\mathrm{q}}\right] \sin \Omega_{\mathrm{T} \mathrm{T}} \mathrm{t}
\end{aligned}
$$

The frequency difference between the two rf fields is given by $\Omega_{\mathrm{r}}$. The ' $\mathrm{T}$ ' spins are offset by $\Omega_{\mathrm{I}}$ from the ' $\mathrm{T}$ ' if field and the ' $S$ ' spins are offset by $\Omega_{\mathrm{s}}$ from the $S$ carrier. This expression includes the influence of the ' $S$ ' $\mathrm{rf}$ on the ' $\mathrm{I}$ ' spins and vice versa (third and sixth terms, respectively). The scalar coupling is retained in full in this equation. The oscillating terms 8 and 9 are, especially for zero- offset cases, synchronous with the rf and it is thus not immediately obvious that they need not be included. Simulations showed, however, that they bave no effect on the transfer in the cases considered.

Simulations show that, with the train of $225^{\circ}$ Gaussian pulses modulated according to the Waltz scheme, and the $\mathrm{I}$ and $\mathrm{S}$ spins separated by $18 \mathrm{kHz}$ (a practical case, see below), maximum transfer takes place at a time corresponding approximately to $1 / \mathrm{J}$ with a good transfer efficiency of 0.9 . Thus, the transfer rate in this 'homonuclear' system behaves as heteronuclear transfer. Figure 4 shows the transfer of magnetization for the different components as a function of resonance offset of both spins from their fixed carriers. We chose the frequency difference and scalar coupling constant between the $\mathrm{S}$ and I spin carricts as $18 \mathrm{kHz}$ and $55 \mathrm{~Hz}$, respectively, in order to simulate transfer between ${ }^{13} \mathrm{C}^{\alpha}$ and ${ }^{13} \mathrm{CO}$. With a train of Gaussian pulses of $0.333 \mathrm{~ms}$, a flip angle of $225^{\circ}$ and peak of amplitude of $4.6 \mathrm{kHz}$, and a mixing time of $18.33 \mathrm{~ms}(\sim 1 / \mathrm{J})$, it is apparent that the behavior is closely simitar to the heteronuclear case described above (Fig. 1). As Fig. 4 illustrates, the transfer from $I_{x}$ to $S_{x}$ is over $80 \%$ complete in the $2.0 \mathrm{kHz} \times 2.0 \mathrm{kHz}$ offset region about the effective carrier frequency, $(90 \%$ over the $1.5 \mathrm{kHz} \times 1.5 \mathrm{kHz}$ offset region). There is little net transfer from $I_{x}$ to $2 S_{x} I_{z}$ and $2 \mathrm{~S}_{\mathrm{y}} \mathrm{I}$, in the same offset region. Some transfer is observed to $S_{y}$, but this term could easily be suppressed if necessary. The simulations show that symmetry is partially lost as the position of the ' $S$ ' carrier influences the ' $I$ ' resonances directly and vice versa. Taken together, we find that well-behaving transfer between two spectral regions can be carried out also in the homonuclear case using $\mathrm{CP}$ with shaped pulses.

Figure 5 shows the effects of field interference in detail. We computed from $\mathrm{Eq} .7$ the efficiency of cross-polarization terms as a function of the ratio of the field separation $\left(\Omega_{\mathrm{rr}}\right)$ over the field strength $\left(\omega_{\mathrm{rf}}\right)$ with $\omega_{\mathrm{ri}}$ constant. When the rf fields are far apart $\left(\Omega_{\mathrm{r}} / \omega_{\mathrm{r} \Gamma}>15\right)$ the shaped cross-polarization behaves as $\mathrm{CW}$ heteronuclear crosspolarization, as it transfers only the component along the field: $I_{x}$ coherence is transferred in $S_{x}$ coherence by the fields along the $\mathrm{x}$-axes (Figs. 5A and $5 \mathrm{~B}$ ), while $\mathrm{I}_{\mathrm{y}}$ coherence is not transferred in this limiting case (Figs. 5C and 5D). The simulations in Fig. 4 were carried out with the parameters $\Omega_{r f}$ of $18 \mathrm{kHz}$ and $\omega_{\mathrm{rf}}$ of $4.6 \mathrm{kHz}$ for a ratio of 3.9 , while most practical applications (see below) were carried out with an $\Omega_{\mathrm{rf}} / \omega_{\text {if }}$ ratio of 3.3. Figure 5 shows that shaped CP under such conditions still essentially behaves as heteronuclear transfer, but that significant orthogonal transfers start to occur. Thus, it is advisable to incorporate purge or $z$-filters around the shaped $\mathrm{CP}$ pulse train with parameters in this regime.

When the rf fields are approaching each other $\left(\Omega_{\mathrm{rr}} / \omega_{\mathrm{rr}}<3\right)$, transfer efficiency and phase behavior become erratic (Figs. 5A-D) and interesting phenomena occur. 

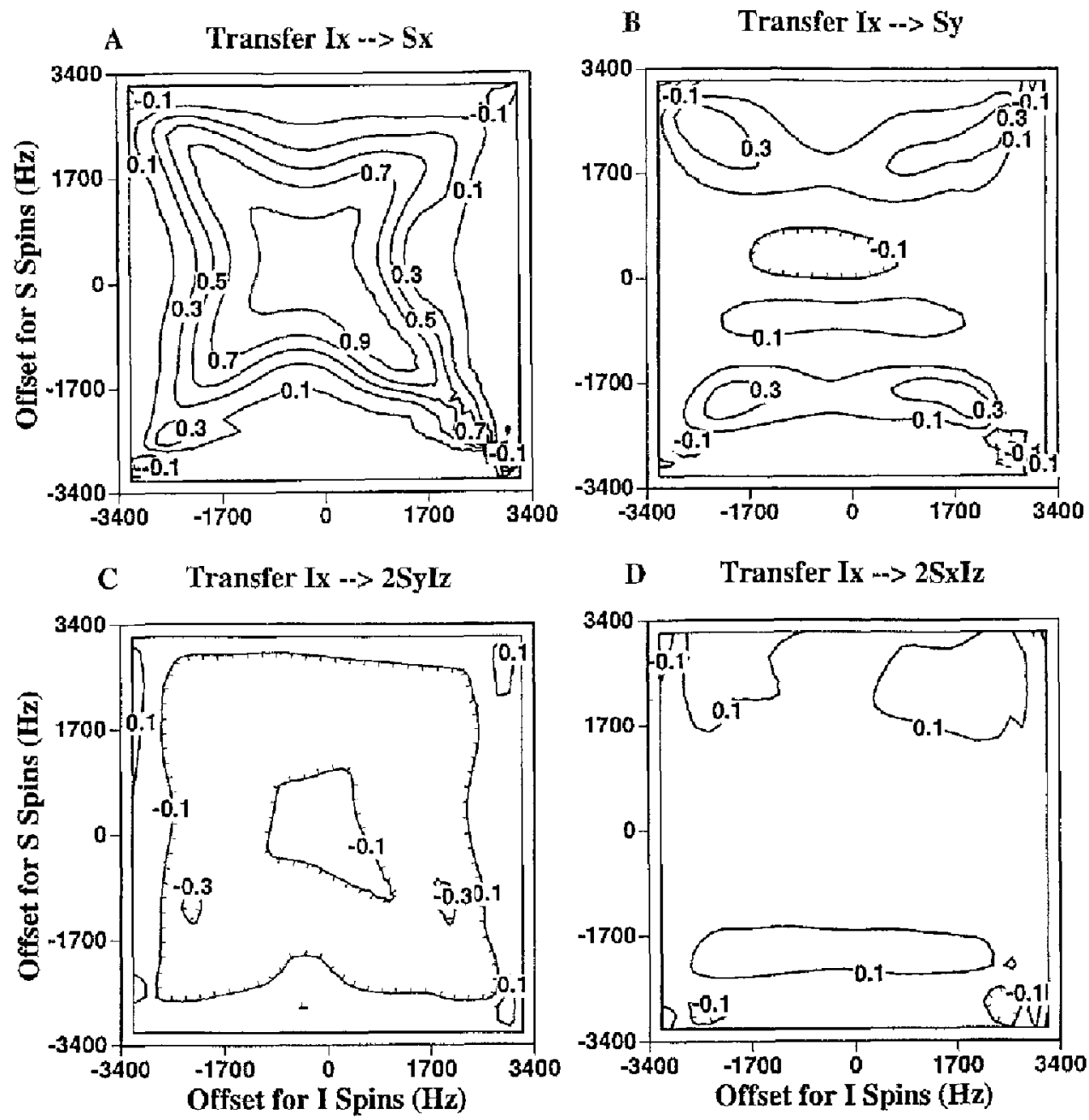

Fig. 4. Simulation of band-selective homonuclear cross-polarization using shaped pulses. The initial density matrix is $I_{x}$, using the Hamiltonian that accounts for the perturbation of the I-spins by the rf field of the S-spins (Eq. 7). A Waitz train of Gaussian rf pulses (truncation leve) $1 \%$ ) along the $\mathrm{x}$-axes of both spins is used with a flip angle of $225^{\circ}$, a pulse length of $0.333 \mathrm{~ms}$, and a peak of of $4.6 \mathrm{kHz}$. The chemical shift difference between the $S$ and $I$ spin carriets is $18 \mathrm{kHz}$, and the scalar coupling constant is $55 \mathrm{~Hz}$. The magnetization components $S_{x}$ (A), $S_{y}$ (B), 2S $\mathrm{I}_{z}(\mathrm{C})$ and $2 S_{n} I_{s}(D)$ are shown as a function of the offsef from thcir fixed carriers for both the donating (I, horizontal axis) and receiving (S, vertical axis) spins at a mixing time of $18.33 \mathrm{~ms}(=1 / \mathrm{J})$.

Transfer up to $80 \%$ can still be obtained, but phasing behavior is different from the pure heteronuclear transfer: with both $C P$ fields along the $x$-axes, both $I_{x}$ and $I_{y}$ can be transferred (Figs. 5A-D). It is possible to choose conditions such that $I_{x} \rightarrow S_{x}$ transfer (see $\boldsymbol{\nabla}$ in Fig. 5A) occurs with approximately equal efficiency as $I_{y} \rightarrow S_{y}$ transfer (see $\checkmark$ in Fig. 5D), reminiscent of homonuclear HartmannHahn (HOHAHA) with a single r[ field. However, since $I_{z}$ is not transferred (data not shown) the behavior is different from HOHAHA (Braunschweiler and Ennst, 1983; Bax and Davis, 1985) and qualifies in this regime neither as homonuclear, nor as heteronuclear $C P$, and thus can be best described as imperfect planar transfer. The choice of experimental parameters in this regime can be necessary when a large bandwidth of transfer is required (e.g. both $\mathrm{C}^{\mathrm{t}}$ and $\mathrm{C}^{\beta}$ transfer with short individual Gaussian pulses in the pulse train requiring a large power, see below). For set-up in the erratic region, it is certainly necessary to incorporate purge or z-filters around the shaped CP pulse train. Simulations of the 'forbidden' transfers as a function of offset and rf power are given in the Supplementary Material.

The erratic behavior is mostly caused by direct influence of one $\mathrm{tf}$ field on the nutation of the other spin. Figure 5E depicts resulting S-spin density matrix terms when a 225 Gaussian $x$-phase pulse is applicd on the $S$ spins (starting from $z$ ) in the presence of another field ' $T$ '. One observes when the ' $I$ ' carrier is far away $\left(\Omega_{\mathrm{T}} / \omega_{\mathrm{r}}>15\right)$ that the $x$-pulse on the $S$-spins results in density-matrix terms closely corresponding to a pure $225^{\circ} \mathrm{x}$-pulse $\left(\mathrm{S}_{\mathrm{x}}=0\right.$; $\left.S_{y}=0.7 ; S_{z}=-0.7\right)$. With the ' $I$ ' carrier closing in, major perturbations occur with an $\Omega_{\mathrm{rr}} / \omega_{\mathrm{rr}}$ ratio of 3 or less, just as is observed for the cross-polarization. Thus, it appears that a search for the ideally shaped pulse in cross-polarization sequences can be directed by a search for the best non-interacting pulse shapes. 

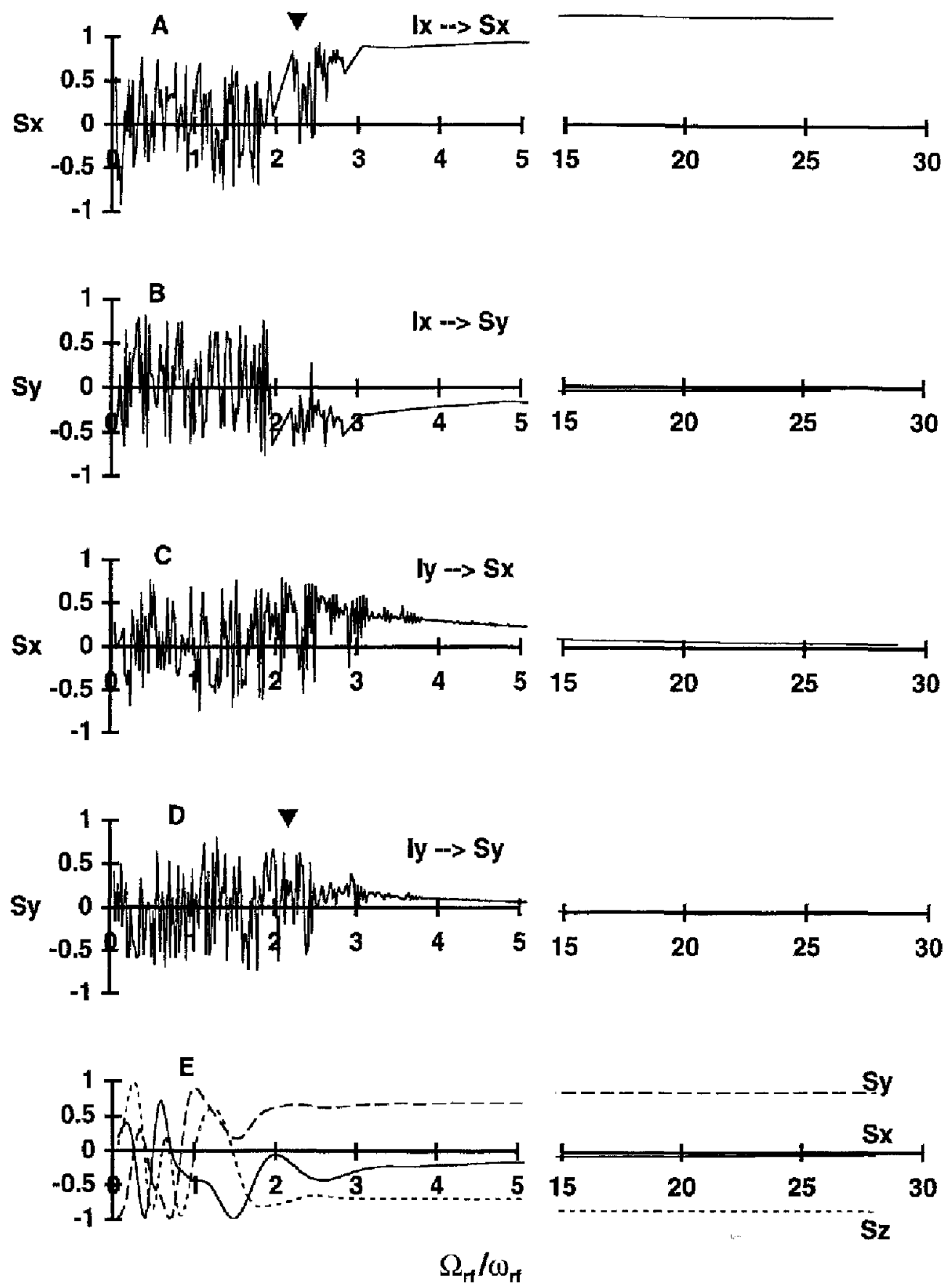

Fig. 5. Simulation of the effect of the separation of the two of carriers on transfer efficiency in shaped homonuclear cross-polarization $\mathrm{I} \rightarrow \mathrm{S}$ using trains of shaped Gaussian pulses as in Fig. 4 . For all panels, the rf fields were kept constant $\left(\omega_{\mathrm{rr}}\right)$ while the rf offset $\left(\Omega_{\mathrm{r}}\right)$ was varied. The transfer sequence was a train of Gaussians with a flip angle of $225^{\circ}$, a pulse length of $0.333 \mathrm{~ms}$, and a peak rf of $4.6 \mathrm{kHz}$; the I and $S$ spins are always on-resonance with their respective if fields; the if fields were always along the $x$-axes of both the $S$ and $I$ resonances. (A) Transfer $I_{x} \rightarrow S_{x}$ (allowed for pure heteronuclear $\mathrm{CP}$ ); (B) transter $\mathrm{I}_{\mathrm{x}} \rightarrow \mathrm{S}_{\mathrm{y}}$ (forbidden for pure heteronuclear $\mathrm{CP}$ ); (C) transfer $\mathrm{I}_{\mathrm{y}} \rightarrow \mathrm{S}_{\mathrm{x}}$ (forbidden for pure heteromclear $\mathrm{CP}$ ); (D) transfer $I_{y} \rightarrow S_{y}$ (forbidden for pure heteronuclear $C P$ ). The arrows in (A) and (D) indicate conditions at which the CSW sequence behaves approximately as a planar transfer path (see text); (E) Tllustration of the influence of the ' $I$ " if field on the nutation of the ' $S$ ' spin. The following Hamiltonian with just two if fields was used: $H(t)=\omega_{r i}^{s}(t) S_{x}+\omega_{i f}^{T}(t)\left[S_{x} \cos \left(\Omega_{r}\right) t-S_{y} \sin \left(\Omega_{r f}\right) t\right]$. The starting density matrix was along $S_{z}$, and $\omega_{r f}^{s}(t)$ and $\omega_{\mathrm{rf}}^{\mathrm{T}}(\mathrm{t})$ were both of Gaussian shape with an (unperturbed) $225^{\circ}$ flip angle.

\section{Verification}

The practical verification of the band-selective homonuclear CP is aimed at use for unidirectional in-phase coherence transfer between ${ }^{13} \mathrm{C}^{\mathrm{c}}$ and ${ }^{13} \mathrm{CO}$. Traditional homonuclear Hartmann-Hahn mixing of ${ }^{13} \mathrm{C}^{\alpha}$ and ${ }^{13} \mathrm{CO}$ at high magnetic fields using only one rf carrier is hardly possible because of the required high-power level to suppress the chemical shift evolution over a spectral width of about $170 \mathrm{ppm}$ (about $21 \mathrm{kHz}$ for a $500 \mathrm{MHz}$ system). Unidirectional, in-phase, ${ }^{13} \mathrm{C}^{\alpha_{-}{ }^{13}} \mathrm{CO}$ transfers are needed in 


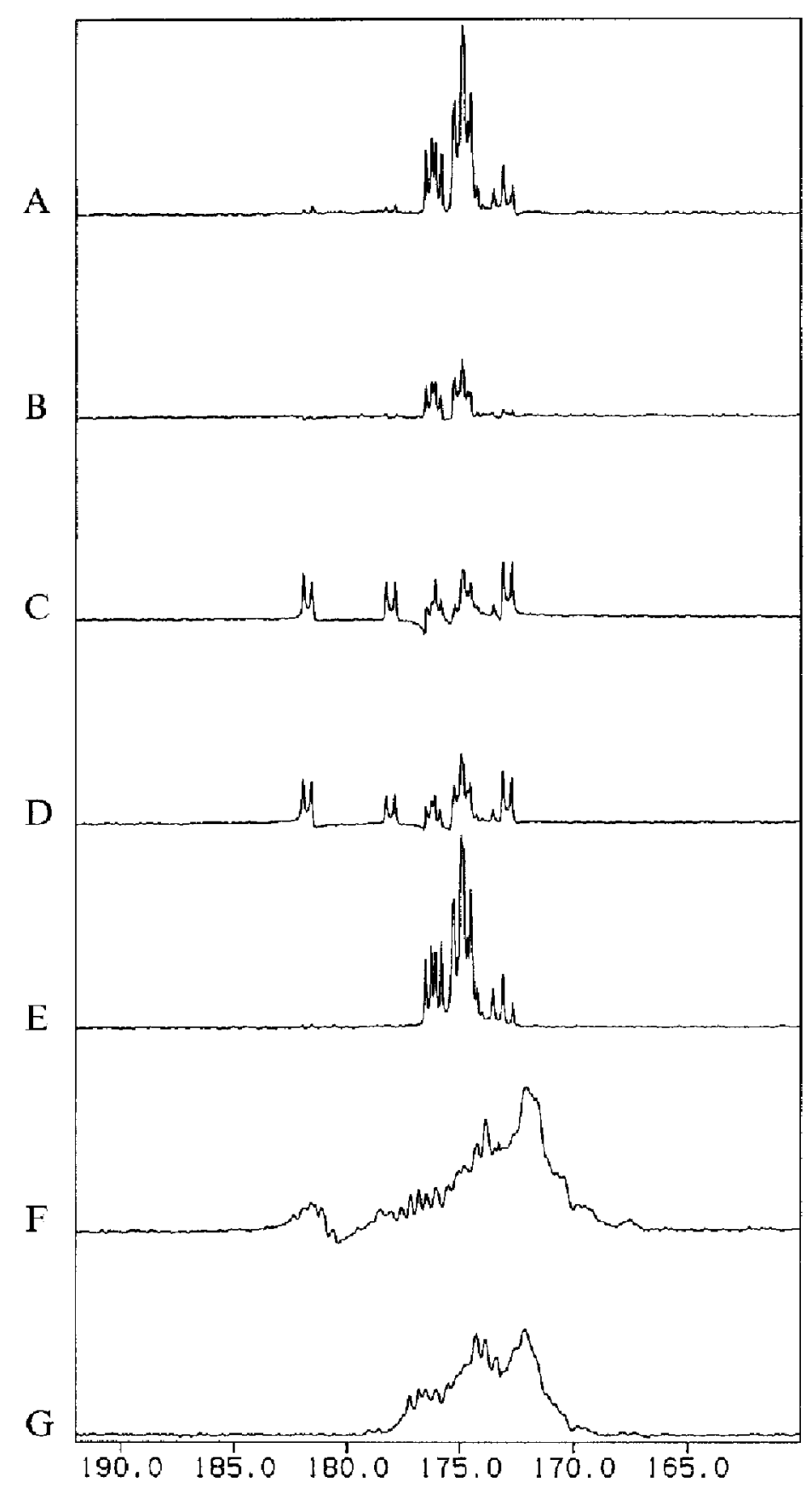

Fig. $6 .{ }^{13} \mathrm{C}$ abserved spectra of the $C O$ region of a labeled amino acid mixture (Cambtidge Isotopes; Figs. $6 A-E$ ) and of the labeled peptide-binding domain of the chapcrone protein Hsc70 (Figs. 6F and G). AII NMR experiments were recorded on a. Bruker AMX500 spectrometer equipped with a triple-resonance gradient probe; only one ${ }^{13} \mathrm{C}$ channel was used and was supplied by a BLAX-300 linear amplifier. The pulse sequence depicted in Fig. 2B was used; refer to that legend for additional experimental details. The same scaling factor is used for panels (A) through (E) and for panels (F) and (G) and no first-order phase correction is applied. (A) and (B) The efficiency of CSW transfer at its maximum (A) and minimum (B) using a train of 333- $\mu \mathrm{s}$ Gaussians of $225^{\circ}$ with an of power of $4.6 \mathrm{kHz}$ per channel (length $18.33 \mathrm{~ms}$ ). The parameters correspond to $\Omega_{\mathrm{rf}} / \omega_{\mathrm{ri}}=$ 3.3. i.e. in the heteronuclear regime (Fig. 5). Maxima and minima were determined by rotating the phase of the first pulse in increments of $10^{\circ}$ and were found to correspond to $140 / 320^{\circ}$ and $50 / 230^{\circ}$, respectively, and hence are separated by $90^{\circ}$ as is expected for pure heteronuclear transfer (sec the legend to Fig. 2B for a more extended discussion of the phase coherences). The phase of the receiver was kept the same in (A) and (B); hence the transfers can be described as predominantly $I_{x} \rightarrow S_{x}$, with a small amount of $I_{y} \rightarrow S_{x}$. (C) and (D) The efficiency of CSW transfer for two orthogonal nagnetization components using a train of $200-\mu \mathrm{s}$ Gaussians of $225^{\circ}$ with an if power of $7 \mathrm{kHz}$ per channel (length $18 \mathrm{~ms}$ ). The parameters correspond to $\Omega_{\mathrm{re}} / \omega_{\mathrm{rf}}=2.3$, thus in the erratic regime (Fig. 5). The transfer is approximately equal at all values for the relative phase of the excitation pulse and the CSW pulse. The phase of the receiver differs by $117^{\circ}$ between Figs. $6 \mathrm{C}$ and $6 \mathrm{D}$; hence the transfers can approximately be described as planar transfer with $\mathrm{I}_{\mathrm{x}} \rightarrow \mathrm{S}_{\mathrm{x}}$ and $\mathrm{I}_{\mathrm{y}} \rightarrow \mathrm{S}_{\mathrm{y}}$. (E) The efficiency of a refocussed INEPT experiment with ${ }^{13} \mathrm{C}^{\alpha}{ }^{13} \mathrm{C}^{\beta}$ decoupling $\left(\mathrm{Fig}_{\mathrm{g}}\right.$. $2 \mathrm{C}$ ) of the same total length $(18.22 \mathrm{~ms})$ and identical other conditions as in $(\mathrm{A})$, transferring ${ }^{13} \mathrm{C}^{(k}$ to ${ }^{13} \mathrm{CO}$ coherence. A control INEPT experiment without ${ }^{13} \mathrm{C}_{-}{ }^{13} \mathrm{C}^{j}$ decoupling was found to be approximately $10 \%$ less sensitive (data not shown). (F) The CSW technique applied to the peptidebinding domain of the chaperone protein $\mathrm{Hsc} 70$ (18 kDa). Parameters as in (A). (G) The resilt of the refocussed INEPT experiment with ${ }^{13} \mathrm{C}^{\alpha}{ }^{13} \mathrm{C}^{\mathrm{b}}$ decoupling (parameters as in (E)) applied to the protein sample described in (F). 


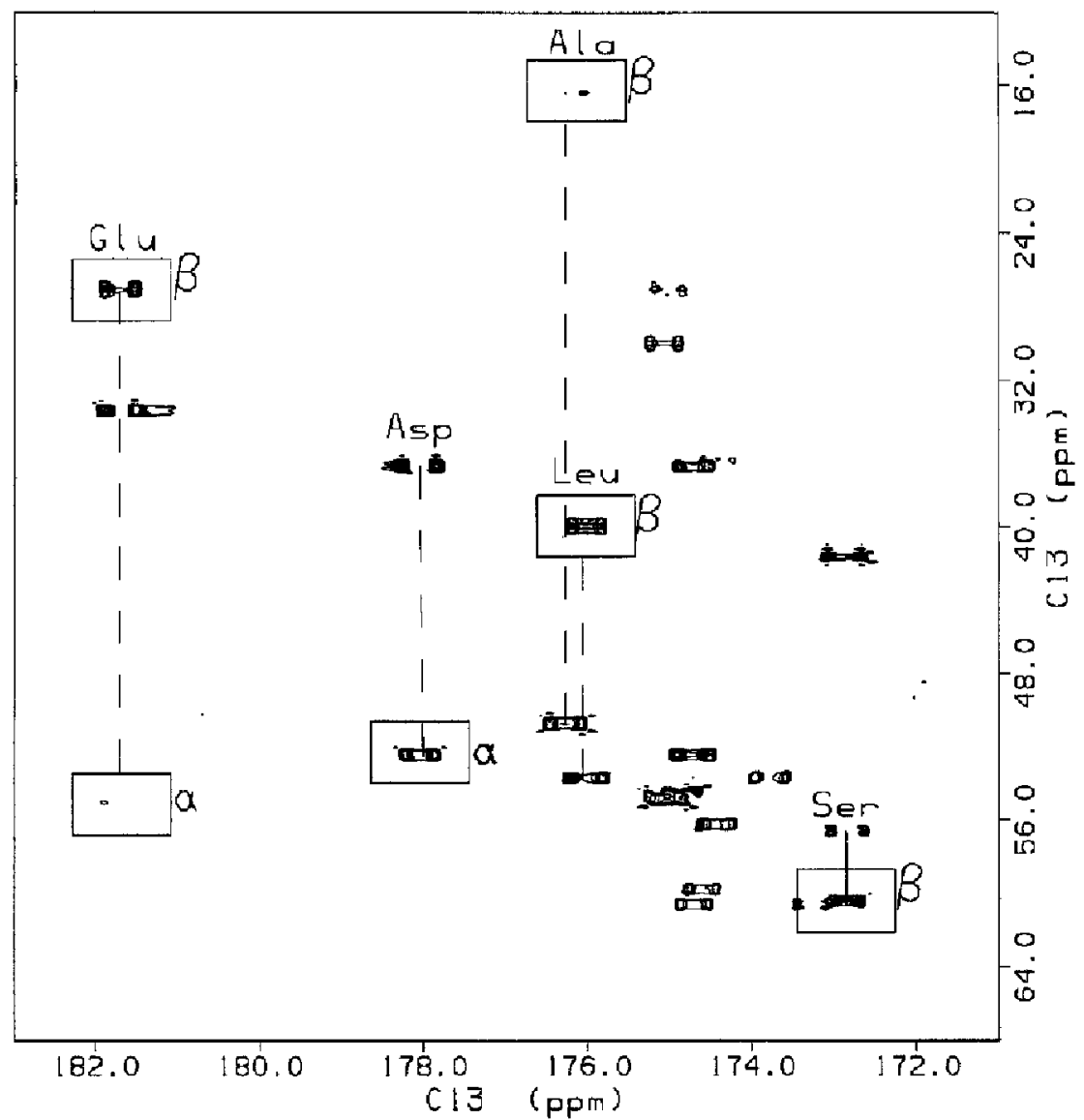

liig. 7. ${ }^{33} \mathrm{C}-{ }^{3} \mathrm{CO}$ correlation spectra of a labeled amino acid mixture recorded with the pulse sechuence of Fig. $2 \mathrm{D}$. A CSW pulse based on 333- $\mu$ s Gaussians is applied for 18.3 ms at a peak power level of $9.2 \mathrm{kHz}$ ( $4.6 \mathrm{kHz}$ per nucleus). Boxes around cross peaks emphasize relayed transfer correlation peaks. No first-order phase correction was applied in F2 (horizontal axis).

(H)C(CACO)NH experiments used for side-chain assignment purposes. In the literature version of the experiment (Clowes et al., 1993; Grzesiek et al., 1993), all coherence transfers are carried out using concatenated refocussed INEPT transfers. The bottleneck is a low sensitivity due to the many transfer steps, especially the ${ }^{13} \mathrm{C}^{\alpha} \rightarrow{ }^{13} \mathrm{CO}$ transfer step because of the fast relaxation of ${ }^{13} \mathrm{C}^{\alpha}$, and the active ${ }^{13} \mathrm{C}^{\alpha}{ }_{-}{ }^{13} \mathrm{C}^{\beta}$ coupling during the INEPT transfer. This coupling yields an apparent magnetization loss of about $25 \%$. Thus the goal is to investigate whether it is possible to supcrpose the homonuclear ${ }^{13} \mathrm{C}^{\alpha}{ }_{-}^{13} \mathrm{C}^{\beta}$ mixing

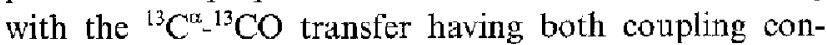
stants acting in a productive manner at the same time. It has been demonstrated recently that simultaneous threespin in-phase magnetization transfer can be achieved by concatenated triple-resonance cross-polarization under Hartmann-Hahn-matching conditions (Majumdar and Zuiderweg, 1995), boding well for the prospects of the current application.

As a first verification, 1D experiments were performed on a mixture of ${ }^{12} \mathrm{C}$-labcled amino acids using the pulse sequence shown in Fig. 2B. Selective pulses are used for the excitation of the aliphatic carbons and ${ }^{13} \mathrm{CO}$ magnetization is detected. It should be emphasized that no filter or purge pulse is applied at the end of the cosine-modulated shaped Waltz mixing sequence ( $\mathrm{CSW}$ ) based on $225^{\circ}$ Gaussian pulses. For the practical implementation of the shaped mixing sequence, we used simple in-house written software. First a 32-point Gaussian pulse (truncation level: $1 \%$ ) was created, then repeated and phase-alternated to get the desired Waltz sequence, including ABBA-type permutation. As mentioned above, a ' 3 ' pulse in the Waltz sequence means in this context three successive $225^{\circ}$ Gaussian pulse shapes of the same phase. Finally, the complete, permuted, Waltz shape is cosine-modulated by the desired shift frequency $\Delta v$ (half the diflerence between ${ }^{13} \mathrm{C}^{\alpha, \beta}$ and ${ }^{13} \mathrm{CO}$ ). The obtained ASCII file is converted to a single shaped pulse with the standard spectrometer software. The cosine modulation automatically creates Iartmann--Hahn matching because the of amplitudes and the phases of the two side bands are exactly the same. The excitation frequency of this pulse can be shifted to the center of the two nuclei by a simple frequency offset (linear phase gradient) on the spectrometer without changing the carrier frequency (see the legend to Fig. 2B for issues pertaining to if phase coherence in these sequences). In this way, a set of different CSW pulses was created based on different Gaussian pulse 
lengths $(200 \mu \mathrm{s}, 300 \mu \mathrm{s}$ and $400 \mu \mathrm{s})$ and with different overall transfer times (4 ms to $30 \mathrm{~ms}$ ). The Waltz sequence was always repeated in $A, A B, A B A, A B B A, \ldots$ schemes. In all three cases the calibration and buildup curves (data not shown) show maximum transfer for a $\mathrm{CSW}$ pulse duration of about $19 \mathrm{~ms}$, corresponding to $1 / \mathrm{J}$ $\left({ }^{13} \mathrm{C}^{\alpha}-{ }^{13} \mathrm{CO}\right)$, in agreement with the simulations. The experimentally determined peak rf power levels for optimum

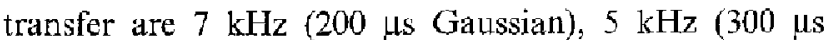
Gaussian) and $3.5 \mathrm{kHz}$ (400 $\mu$ s Gaussian) per side band, in good agreement with a $225^{\circ}$ rotation for an individual Gaussian pulse.

Figures $6 \mathrm{~A}$ and $6 \mathrm{~B}$ show that excellent phase behavior is obtained when selective Gaussians are used $(333 \mu \mathrm{s})$ with a $\Omega_{\mathrm{ri}} / \omega_{\mathrm{rf}}$ ratio of 3.5 and the excitation pulse and low-frequency band of the CSW pulse in the center of the $\mathrm{C}^{\alpha}$ region. With the pulse sequence depicted in Fig. 2B, $I_{x}$ magnetization $\left(C^{\infty}\right)$ is transferred predominantly to $S_{x}$ magnetization $(\mathrm{CO})$, while only a small fraction of $\mathrm{I}_{y}$

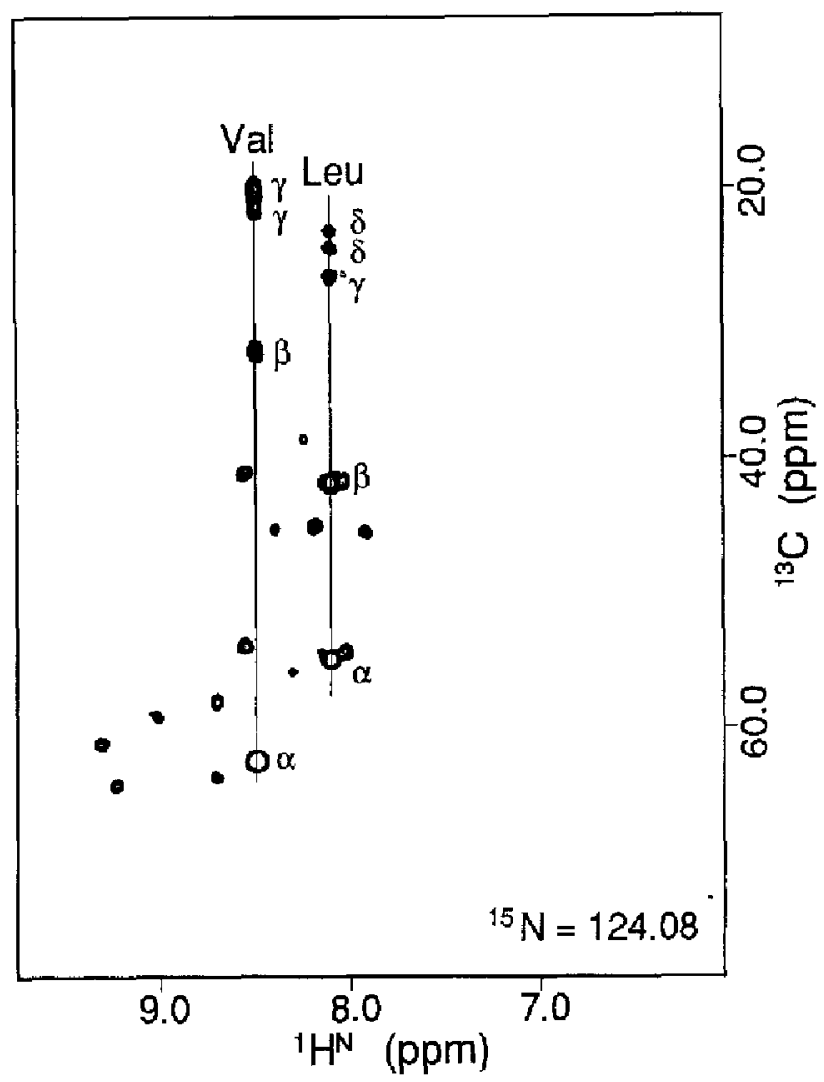

Tig. 8. ' $\mathrm{Fr}{ }^{\mathrm{N}}{ }^{3} \mathrm{C}$ plane of the 3D (II)C(CCO)NH data set using the pulse sequence of Fig. $2 \mathrm{E}$ taken at a ${ }^{15} \mathrm{~N}$ frequency of $124 \mathrm{ppm}$. A

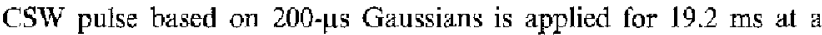
peak power level of $14 \mathrm{kHz}$ ( $7 \mathrm{kHz}$ per nucleus). A data matrix of $75\left(t_{1}\right) \times 25\left(t_{2}\right) \times 512\left(t_{3}\right)$ complex points was recorded. Acquisition times were $7.5 \mathrm{~ms}\left(\mathrm{t}_{1}\right), 20 \mathrm{~ms}\left(\mathrm{t}_{2}\right)$ and $93 \mathrm{~ms}\left(\mathrm{t}_{3}\right)$ and the overall experimental time was $70 \mathrm{~h}$. After apodization and zero-illing the data were Fourier-trausformed to a final $256 \times 64 \times 512$ matrix. The sample contained $1.5 \mathrm{~m} \mathrm{M} \mathrm{Hsc}-70$ peptide binding domain $\left(18 \mathrm{kDa}, \tau_{\mathrm{s}}=14 \mathrm{~ns}\right)$ at $20^{\circ} \mathrm{C}$, pH 7.0 in $50 \mathrm{mM}$ phosphate. Two residues (Val and Leu) are seen in this plane and all ${ }^{13} \mathrm{C}$ resonances are identified. magnetization is transferred and emerges as $\mathrm{S}_{x}$. This behavior corresponds with the simulations shown in Figs. $5 \mathrm{~A}$ and $5 \mathrm{C}$ respectively. It is emphasized that the phase of the receiver is the same for Figs. 6A and 6B. The terms $x$ and $y$ are operationally defined since the phase relationship between the different pulses, spins and receivers is a priori unknown (see legend to Fig. 2B). Some $I_{x}$ magnetization is translerred to $\mathrm{S}_{\mathrm{y}}$ (as in Fig. 5B) and antiphase terms, as is evident from both the slight phase distortions and differences in intensity of the ${ }^{13} \mathrm{CO}$ doublet components (Fig. 6A).

Figures $6 \mathrm{C}$ and $6 \mathrm{D}$ demonstrate that approximately planar phase behavior occurs when less selective 200-us Gaussians are used $\left(\Omega_{\mathrm{rr}} / \omega_{\mathrm{rr}}\right.$ ratio of 2.3$)$ : both $\mathrm{I}_{\mathrm{x}}$ and $\mathrm{I}_{\mathrm{y}}$ components can be transferred with the rf fields along both the $x$-axes and are transferred to approximately orthogonal $S_{x}$ and $S_{y}$ components. It is emphasized that the phase of the receiver is $117^{\circ}$ different between Figs. $6 \mathrm{C}$ and $6 \mathrm{D}$. This behavior corresponds with the simulations shown in Figs. 5A and 5D, respectively, where for $\Omega_{\mathrm{rf}} / \omega_{\mathrm{r}}<3$ conditions can be found where transfer is approximately planar (e.g. at the positions of the arrows; see also above). It is thus concluded that the experimental band-selective homonuclear cross-polarization experiments are in very good agreement with the theoretical predictions. For this experiment, the excitation pulse and lowlrequency band of the CSW pulse were in between the $\mathrm{C}^{a}$ and $C^{\beta}$ region. It is clear that the sensitivity of transfer is significantly lower than the experiment where the lowfrequency carrier is at the center of $\mathrm{C}^{*}$ (Figs. 6A and 6E).

Comparison with a transfer sequence based on refocussed INEPT (Fig. 6E) shows that for this sample (where relaxation can be neglected) equal sensitivity is obtained for both techniques. The refocussed INEPT sequence suppressed ${ }^{13} \mathrm{C}^{\beta}{ }_{-}^{13} \mathrm{C}^{\alpha}$ scalar coupling (Fig. 2C). Figures $6 \mathrm{~F}$ and $6 \mathrm{G}$ show a similar comparison for the peptidebinding domain of the chaperone protein $\mathrm{Hsc} 70$ (18 $\mathrm{kDa}$; $\tau_{\mathrm{R}}=14 \mathrm{~ns}$ ), demonstrating that the $\mathrm{CP}$ sequence has a slightly larger amplitude and bandwidth than the refocussed, decoupled INEPT sequence.

The minimal improvement in sensitivity for the CP sequence is somewhat disappointing. However, with CP it is possible to choose the placement of the if carrier such that simultaneous homonuclear cross-polarization takes place during the heteronuclear transfer (e.g. $\mathrm{C}^{\beta}, \mathrm{C}^{\alpha}, \mathrm{CO}$ ). This is shown in Fig. 7, where the placement of one of the cosine components of the if ficld in the middle of the $\mathrm{C}^{\beta}$ and $C^{\alpha}$ region, yielding several two-step transfers (see boxed cross peaks; pulse sequence given in Fig. 2D). The CSW pulsc used is based on 333- $\mu$ s Gaussians and secms to be a good compromise between sensitivity and transfer band width for this sample ( $30 \mathrm{ppm})$. Even though relayed transfers do occur with CSW mixing only, better results can be obtained when the CSW mixing is preceded by a homonuclear ${ }^{13} \mathrm{C}-{ }^{13} \mathrm{C}$ Hartmann-Hahn transfer (data not 

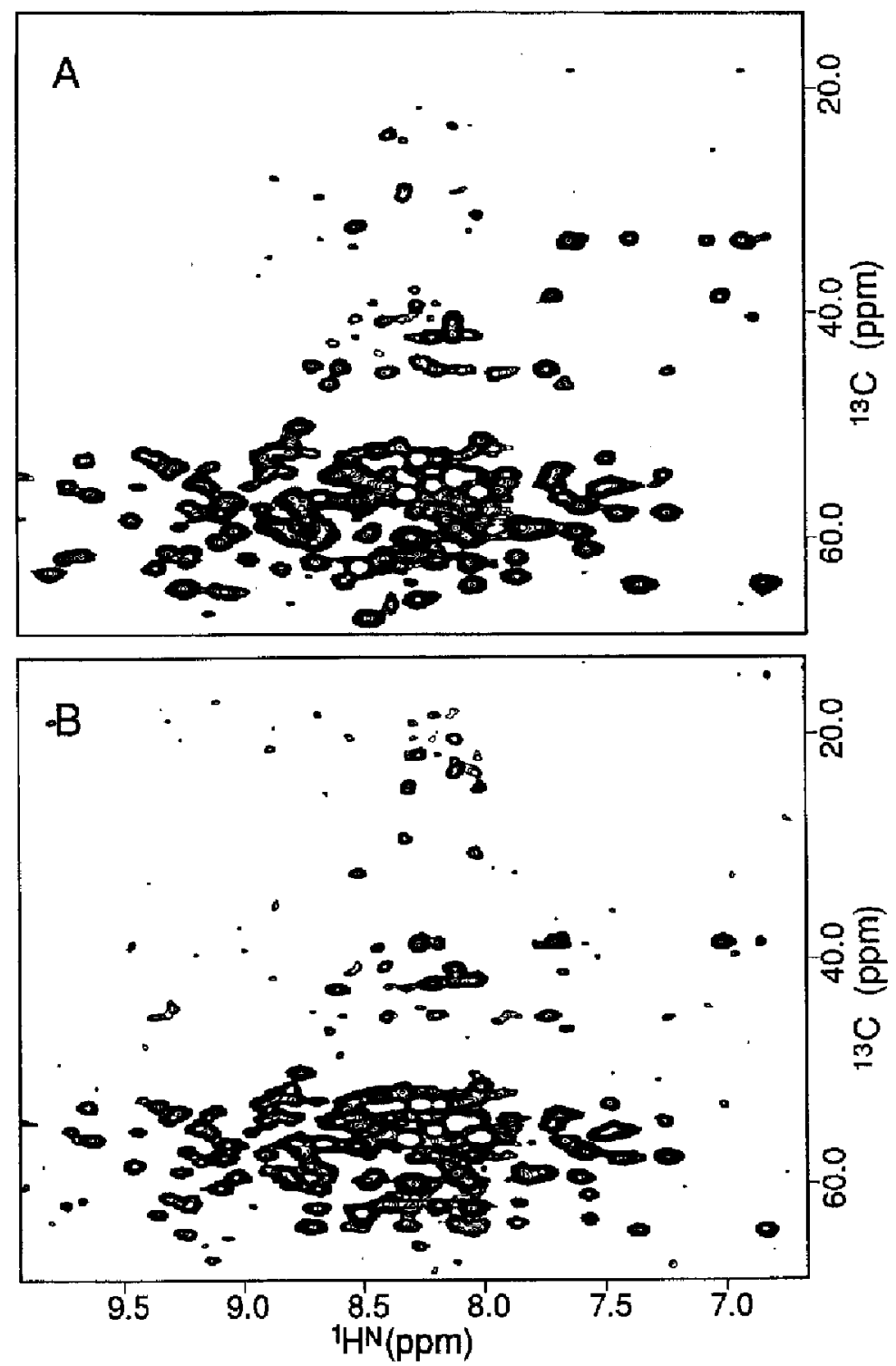

Fig. 9. 2D versions of the (I)C(CCO) NH experiment (no ${ }^{15} \mathrm{~N}$ labeling) recorded with an INEPT-based pulse sequence without $\mathrm{C}^{\beta}$ decoupling (A) and the CSW pulse sequence of Fig. 2E (B) using the Hsc-70 peptide binding domain sample as described in Fig. 8. Both experiments were recorded with an additional short ${ }^{13} \mathrm{C}$ mixing of $6 \mathrm{~ms}$ and an overall experimental time of $30 \mathrm{~h}$.

shown). This transfer can have limited duration, as it is only used to boost the performance of the CSW sequence.

Summarizing, we show with the amino acid mixture that in-phase transfer of magnetization between $C^{c}$ and $\mathrm{CO}$ is possible using a train of Gaussian pulses of $225^{\circ}$. The transfer is over a wide bandwidth, has excellent phasing behavior at low-power settings, and its efficiency is encouraging enough to investigate the mechanism as a transfer step in the application on a labeled protein. Another incentive for the application of CSW pulses is the possibility of sensitivity improvement as chemical exchange line-broadening effects are suppressed (Krishnan and Rance, 1995).

\section{Application}

Once proven that in-phase transfer ${ }^{13} \mathrm{C}^{\mathrm{C}, 3} \rightarrow{ }^{13} \mathrm{CO}$ is possible, the application of the CSW mixing scheme in a (H)C(CCO) NH experiment is straightforward. Figure $2 \mathrm{E}$ shows the pulse sequence used to record a 3D data set using a $1.5-\mathrm{mM}$ sample of the $18-\mathrm{kDa}$ peptide-binding domain of the chaperone protein Hsc (this protein behaves as a relatively large system with a rotational correlation time of $14 \mathrm{~ns})$. The transfer pathway for a $\left(\mathrm{C}_{\psi}, \mathrm{N}, \mathrm{H}^{\mathrm{N}}\right)$ correlation is the following:

$$
\begin{aligned}
& 1 \mathrm{H}_{(j)}^{\gamma} \rightarrow(\mathrm{CP}) \rightarrow{ }^{13} \mathrm{C}_{(\mathrm{j})}\left(\mathrm{t}_{1}\right) \rightarrow(\text { Hartmann-Hahn }) \rightarrow \\
& { }^{17} \mathrm{C}_{(j)}^{\beta, \alpha} \rightarrow(\mathrm{CSW}) \rightarrow{ }^{13} \mathrm{CO}_{(0)} \rightarrow(\text { INEPT }) \rightarrow{ }^{15} \mathrm{~N}_{(\mathrm{i}+1)}\left(\mathrm{t}_{2}\right) \rightarrow \\
& (\mathrm{INEPT}) \rightarrow{ }^{1} \mathrm{H}_{(j+1)}^{\mathrm{N}}\left(\mathrm{t}_{3}\right)
\end{aligned}
$$

For the first ${ }^{1} \mathrm{H}^{13} \mathrm{C}$ transfer step a square-pulse $\mathrm{CP}$ mixing sequence was chosen because of a lower sensitivity to $\mathrm{RF}$ inhomogeneity and a more uniform excitation of 
the different $\mathrm{CH}_{\mathrm{a}}$ groups (Majumdar et al., 1993). The homonuclear ${ }^{13} \mathrm{C}$ mixing is achieved during a z-filter using a Waltz-16 sequence of $11.6 \mathrm{~ms}$. Good water suppression was achieved using pulsed field gradients after the homonuclear ${ }^{13} \mathrm{C}$ mixing to dephase the water resonance and as a $z$-filter before detection (Wang and Zuiderweg, 1995). Additional $\mathrm{CW}$ irradiation and trim pulses during the transfer steps not involving $\mathrm{H}$ magnetization were found to further improve the water suppression. CSW mixing with the carrier positions in the middle of the ${ }^{13} \mathrm{C}^{\mathrm{\alpha}, \beta}$ region and on the ${ }^{13} \mathrm{CO}$ region, was applied during $19.2 \mathrm{~ms}$. In order to capture the larger spectral dispersion of signals in a protein spectrum, a CSW pulse based on $200 \mu \mathrm{s}$ Gaussians was used ( $7 \mathrm{kHz}$ of per sideband). With a separation over the rf field ratio of 2.3 , this CSW pulse is in the erratic regime (Figs. $5 \mathrm{~A}-\mathrm{D}$ ), and interactive phase optimization of several pulses had to be carried out. This choice gives a good bandwidth of transfer, but suffers in sensitivity as compared to a $\mathrm{C}^{\alpha}$-selective carrier position.

Figures 8 and 9 show that the shaped pulse $\mathrm{CP}$ in this erratic regime is sufficiently reproducible to be used for long-term data acquisitions for the 3D experiment. Figure 8 shows one $\left({ }^{1} \mathrm{H}^{\mathrm{N}},{ }^{13} \mathrm{C}\right)$ plane of the obtained 3D data set. Two longer side-chain residues (Val and Leu) can easily be identified and prove that correlations up to the $\delta$-methyls of leucine are obtained with this pulse sequence and the relatively short ${ }^{13} \mathrm{C}$ mixing time of $11.6 \mathrm{~ms}$.

To compare the sensitivity of this pulse sequence with an INEPT version (for ${ }^{13} \mathrm{C}^{\alpha} \rightarrow{ }^{13} \mathrm{CO}$ transfer), $2 \mathrm{D}$ versions were recorded with a shorter homonuclear mixing time of $6 \mathrm{~ms}$ (Figs. 9A and B). The INEPT experiment is optimized for $\mathrm{C}^{\alpha} \rightarrow \mathrm{CO}$ transfer, while the CSW experiment is optimized for $\mathrm{C}^{\alpha, 3} \rightarrow \mathrm{CO}$ transfer, expecting simultaneous $C^{\alpha . \beta}$ transfer at the expense of lower sensitivity (see Figs. 6C and 6D). For the INEPT version the CSW mixing was replaced by a refocussed INEPT step (no $\mathrm{C}^{\alpha}-\mathrm{C}^{\beta}$ decoupling). The ${ }^{13} \mathrm{CO}^{13} \mathrm{C}^{\alpha}$ refocussing period was overtaid with the ${ }^{13} \mathrm{CO} \rightarrow{ }^{15} \mathrm{~N}$ transfer step of $13 \mathrm{~ms}$, as e.g. described by Grzesiek et al. (1993). The transfer delay $1 / 4 \mathrm{~J}\left({ }^{13} \mathrm{C}^{\alpha} \rightarrow{ }^{13} \mathrm{CO}\right)$ was optimized to $3 \mathrm{~ms}$. In the INEPT version, the magnetization thus resides on ${ }^{13} \mathrm{C}^{\alpha}$ for $6 \mathrm{~ms}$ and on ${ }^{13} \mathrm{CO}$ for $13 \mathrm{~ms}$. For the CSW version the magnetization is spinlocked for $19.2 \mathrm{~ms}$ during the ${ }^{13} \mathrm{C}^{\mathrm{\alpha c}, \beta} \rightarrow{ }^{13} \mathrm{CO} \mathrm{CSW}$ step and subsequently also resides for $13 \mathrm{~ms}$ on ${ }^{13} \mathrm{CO}$ (the delay ' $\triangle$ ' in Figs. 2D and 2E). During the CSW pulse, the relaxation rate of the locked magnetizations is expected to be the average of the relaxation rates of the ${ }^{13} \mathrm{C}^{\alpha}$ and ${ }^{13} \mathrm{CO}$ spins (Majumdar and Zuiderweg, 1995). Consequently, for ${ }^{13} \mathrm{C}^{\alpha}$ resonances showing fast relaxation sensitivity is lost in the CSW experiment due to the longer effective residence time of the coherence on that nucleus. This is clearly seen (Fig. 9) for the ${ }^{13} \mathrm{C}^{-6}$ of glycines (at about 45 ppm) and the $\mathrm{NH}_{2}$ side chains. Nevertheless, supplementary correlation pcaks are seen in the CSW-based experi- ment (Fig, 9), showing that for narrower resonances the transfer is improved.

\section{Conclusions}

We have demonstrated, by simulation and experiment, that in-phase cross-polarization can be produced between scalar coupled spins that are normally classified as a homonuclear system, using two synchronous, multiple shaped-pulsed fields. We conclude that a sequence of Gaussian pulses with a nominal flip angle of $225^{\circ}$, modulated in a Waltz-type pattern gives rise to good transfer efficiency. We have determined that shaped cross-polarization can behave as pure heteronuclear cross-polarization when the two rf fields are far apart, while it behaves somewhat reminiscent of homonuclear cross-polarization with a single field when the two rf fields approach each other. The optimum power levels and flip angles, as obtained by us, are remarkably similar to those used by Carlomagno et al. (1996); only the modulation scheme is different. Our CSW transfer may be used in the context of triple-resonance experiments incorporating ${ }^{13} \mathrm{C}^{\alpha 2}-{ }^{13} \mathrm{CO}$ transfers, where, as an additional benefit, homonuclear ${ }^{13} \mathrm{C}^{\mathrm{\beta}}-13 \mathrm{C}^{\alpha}$ transfer occurs simultaneously. In principle, this approach may also be used for other applications, such as ${ }^{13} \mathrm{C}-{ }^{13} \mathrm{C}$ transfers in nucleic acids and in aromatic amino acids. The sequence will need to be critically fine-tuned for every application.

\section{Acknowledgements}

We thank Drs. M. Ravikumar and A. Majumdar for encouraging discussions. We thank Dr. Gregory Flynn for the labeled Hsc-PBD protein sample. This work was carried out with support of NSF grants MCB 9218573 and 9513355 . B.B. acknowledges support from C.E.A. and Bruker Analytische Messtechnik.

\section{Note added in proof}

We have now also obtained good transfer $\mathrm{C}^{\mathrm{y}, \mathrm{g}, \mathrm{s}} \rightarrow \mathrm{C}^{\beta}$ in aromatic residues using a $16.65 \mathrm{~ms}$ cosine-modulated ABBABAAB sequence of $225^{\circ}$ Gaussian pulses of $333 \mu \mathrm{s}$ each $(4.2 \mathrm{kHz}$ peak $\mathrm{rf})$.

\section{References}

Artemov, D., Bhujwalla, Z.M. and Glickson, J.D. (1995) J Magn. Reson, B107, 286-288.

Bax, A and Davis, D.G. (1985) J. Magn. Reson., 65, 355-360.

Bearden, D.W. and Brown, L.R. (1989) Chem. Phys. Lett., 163, 432436

Bertand, R.D., Moniz, W.B., Garroway, A.K. and Chingas, G.C. (1978) I Am. Chem. Soc, 100, 5227-5229.

Braunschweíler, L. and Emst, R.R. (1983) $J$. Magn. Reson, 53, 521528. 
Brown, L.R. and Sawctuary, J. (1991) J. Magn. Reson, 91, 413-421. Carlomagno, T., Maurer, M., Sattler, M., Schwendinger, M.G., Glaser, S.J. and Griesinget, C. (1996) J. Bionol. NMR, 8, 161-170. Clowes, R.T., Boucher, W., Hardman, C.H., Domaille, P.J. and Laue, E.D. (1993) $d$ Biomol. NMR, 3, 349-354.

Emsley, L, and Bodenhausen, G. (1989) J. Magn. Reson, 82, 211-221. Emsley, L. and Bodenhausen, G. (1990) Chem. Phys. Lett., 165, 469471.

Ernst, M., Griesinger, C., Bermel, W. and Erust, R.R. (1991) Mol. Phys, 74, 219-252.

Farmer III, B,W (1995) Frontiers of NMR in Molecular Biology IV, Keystone, $\mathrm{CO}$.

Grzesiek, S, Anglister, I. and Bax, A, (1993) I Magn. Reson, R101, 114-119.

Grzesiek, S. and Bax, A. (1995) J. Am Chem Soc, 117, 6527-6531. Kay, L.E., Ikura, M. and Bax, A. (1991) J. Magn. Resen, 91, 84-92. Kellog, G.W. (1992) J Magn. Reson., 97, 623-627.

Kellog, G.W. and Schwettzer, B.I. (1993) J. Biomol. NMR, 3, 577-595.

Konrat, R., Burghardt, I. and Bodenhausen, G. (1991) J. Am Chem. Soce, 113, 9135-9140.

Krishnan, V.V. and Rance, M. (1995) $J$ Magn. Reson, A116, 97-106. Levitt, M.H., Freeman, R and Frenkiel, T.I. (1982) $J$ Magn. Reson., 47, 328330 .

Majumdar, A, Wang, H., Morshauser, R,C and Zuiderweg. E.R.P. (1993) I. Biomol. NMR, 3, 387-397.

Majumdar, A. and Zuiderweg, E.R.P. (1995) J. Magn. Reson., A113, $19-31$.
Mariani, M., Tessari, M., Boelens, R., Vis, H. and Kaptein, R. (1594) J. Magn. Reson, B104, 294-297.

Marion, D., Ikura, M., Tschudin, R. and Bax, A. (1989) J. Magn. Reson, 85, 393-399.

MoCoy, M.A. (1995) J. Magn. Reson., B107, $270-273$.

Müller, L. and Ernst, R.R. (1979) Mol. Phys, 38, 363-992.

Quant, J., Prasch, T., Thringer, S. and Glaser, S.J. (1995) $d$. Magn. Reson., B106, 116-121.

Richardson, J.M., Clowes, R.T., Boucher, W., Domaille, P.J., Ilardman, C.H., Keeler: J. and Laue, E.D. (1993) J. Magr. Reson, B101, 223-227.

Schwendinger, M.G., Quant, J., Schleucher, J., Glaser, S.J. and Griesinger, C. (1994) I. Magm. Rewo, A 111, 115-120.

Shaka, A.J., Keeler, C, Frenkiel, T. and Freeman, R. (1983) J. Magn. Reson., 52, 335-338.

Shaka, A.J., Lee, C.J. and Pines, A. (1988) J. Magn. Reson., 77, 274293.

Shirakawa, M., Walchli, M., Shimizu, M. and Kyogoku, Y. (1995) J. Biomol. NMR, 5, 323-326.

Vincent, SJ,F., Zwahlen, $\mathrm{C}$ and Bodenhausen, $\mathrm{G}$ (1993) $J$ Am. Chem. Soc. 115, 9202-9209.

Wang, H. and Zuiderweg, E.R.P. (1995) J. Biomol. NMR, 5, 207.211. Wijmenga, S.S., Heus, H.A., Leeuw, H.A.E., Hoppe, H., Van der Graaf, M. and Hilbers, C.W. (1995) .7. Biumol NMR, 5, 82-86.

Zuiderweg, E.R.P. (1990) J. Magn. Reson., 89, 533-542.

Zuiderweg, E, R, P. (1994) XVIth International Conference on Magnetic. Resonaice in Biological Systoms, Veldhoven, The Netherlands. 